\title{
A Case of Cutaneous Myiasis Caused by Cordylobia anthropophaga Larvae in a Korean Traveler Returning from Central Africa
}

\author{
Joo Yeon Ko', In-Yong Lee², Byeong Jin Park', Jae Min Shin', Jae-Sook Ryu3,** \\ 'Department of Dermatology, Hanyang University College of Medicine, Seoul 04763, Korea; ${ }^{2}$ Department of Environmental Medical Biology, and \\ Institute of Tropical Medicine, Yonsei University College of Medicine, Seoul 03722, Korea; ${ }^{3}$ Derpartment of Environmental Biology and Medical \\ Parasitology, Hanyang University College of Medicine, Seoul 04763, Korea
}

\begin{abstract}
The cutaneous myiasis has been rarely reported in the Republic of Korea. We intended to describe here a case of furuncular cutaneous myiasis caused by Cordylobia anthropophaga larvae in a Korean traveler returned from Central Africa. A patient, 55-year-old man, had traveled to Equatorial Guinea, in Central Africa for a month and just returned to Korea. Physical examinations showed 2 tender erythematous nodules with small central ulceration on the left buttock and thigh. During skin biopsy, 2 larvae came out from the lesion. C. anthropophaga was identified by paired mouth hooks (toothed, spade-like, oral hooklets) and 2 posterior spiracles, which lack a distinct chitinous rim. Although rarely described in Korea until now, cutaneous myiasis may be encountered more frequently with increasing international travel and exchange workers to tropical areas.
\end{abstract}

Key words: Cordylobia anthropophaga, cutaneous, myiasis, Central Africa

\section{INTRODUCTION}

Myiasis is characterized as the infestation of any living tissue of vertebrate animal including human that can involve cutaneous, enteric, ophthalmic, nasopharyngeal, auricular, and urogenital systems by larvae of the order of Diptera (true flies) [1]. Cutaneous myiasis is the most common form and it is clinically divided into 3 types, i.e., wound, migratory (creeping) and furuncular, depending on the species of infesting larvae [2]. Among the 3 clinical types of cutaneous myiasis, the furuncular type is mainly caused by the larvae of Cordylobia anthropophaga, Dermatobia hominis, Cuterebra sp., and Wohlfahrtia sp. [1]. This dermatological disease by C. anthropophaga larvae is commonly occurred in tropical Africa through skin contact with the ground contaminated with the fly larvae [3]. Until now, total 3 imported cases of cutaneous myiasis have been reported in the Republic of Korea (Korea) [4-6]. However, this exotic disease may be encountered more frequently with in-

- Received 11 January 2018, revised 19 February 2018, accepted 3 March 2018.

*Corresponding author (jsryu@hanyang.ac.kr)

(c) 2018, Korean Society for Parasitology and Tropical Medicine

This is an Open Access article distributed under the terms of the Creative Commons Attribution Non-Commercial License (http://creativecommons.org/licenses/by-nc/4.0) which permits unrestricted non-commercial use, distribution, and reproduction in any medium, provided the original work is properly cited. creasing travel opportunity in endemic tropical areas. Therefore, we intended to report here a case of furuncular myiasis caused by $C$. anthropophaga larvae in a Korean traveler returning from Equatorial Guinea.

\section{CASE RECORD}

A 55-year-old man presented to the dermatology outpatient clinic at Hanyang University Seoul Hospital, with 1-week history of 2 painful erythematous nodules on the left buttock and upper thigh (Fig. 1). He was usually very healthy with no underlying systemic diseases but had a traveling history to Equatorial Guinea, Central Africa for a month and just returned to Korea. On physical examination, there were 2 tender, erythematous indurated nodules with small central ulceration.

Laboratory tests demonstrated normal white blood cell count $\left(6,700 / \mathrm{mm}^{3}\right)$ with neutrophils $(54.7 \%)$, normal hemoglobin $(12.9 \mathrm{~g} / \mathrm{dl})$ and platelet count $\left(288,000 / \mathrm{mm}^{3}\right)$. The tests also revealed normal aspartate aminotransferase, creatinine and erythrocyte sedimentation rate (ESR) with values of 20 U/L (normal: 7-38), 1.07 mg/dl (0.5-1.2), 15 mm/hr (020), respectively. However, the C-reactive protein (CRP) level, $1.2 \mathrm{mg} / \mathrm{dl}(<0.5)$, was more or less increased.

Histopathologic examination of the left buttock showed 


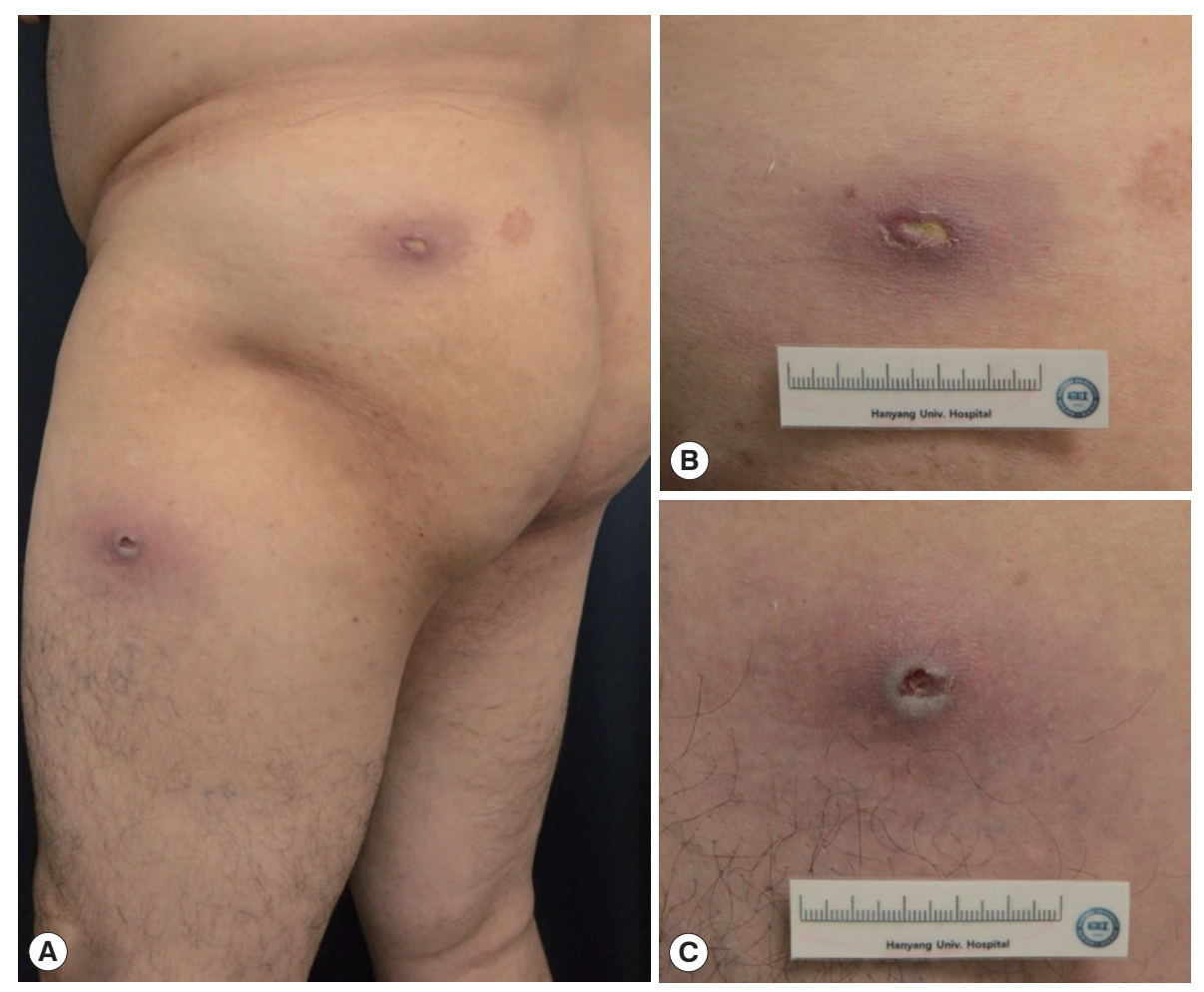

Fig. 1. (A) Cutaneous examination showed two erythematous nodules with small central ulceration on the left buttock and thigh. (B, C) Incisional biopsies were performed on both erythematous ulcerative nodules along their major axis.
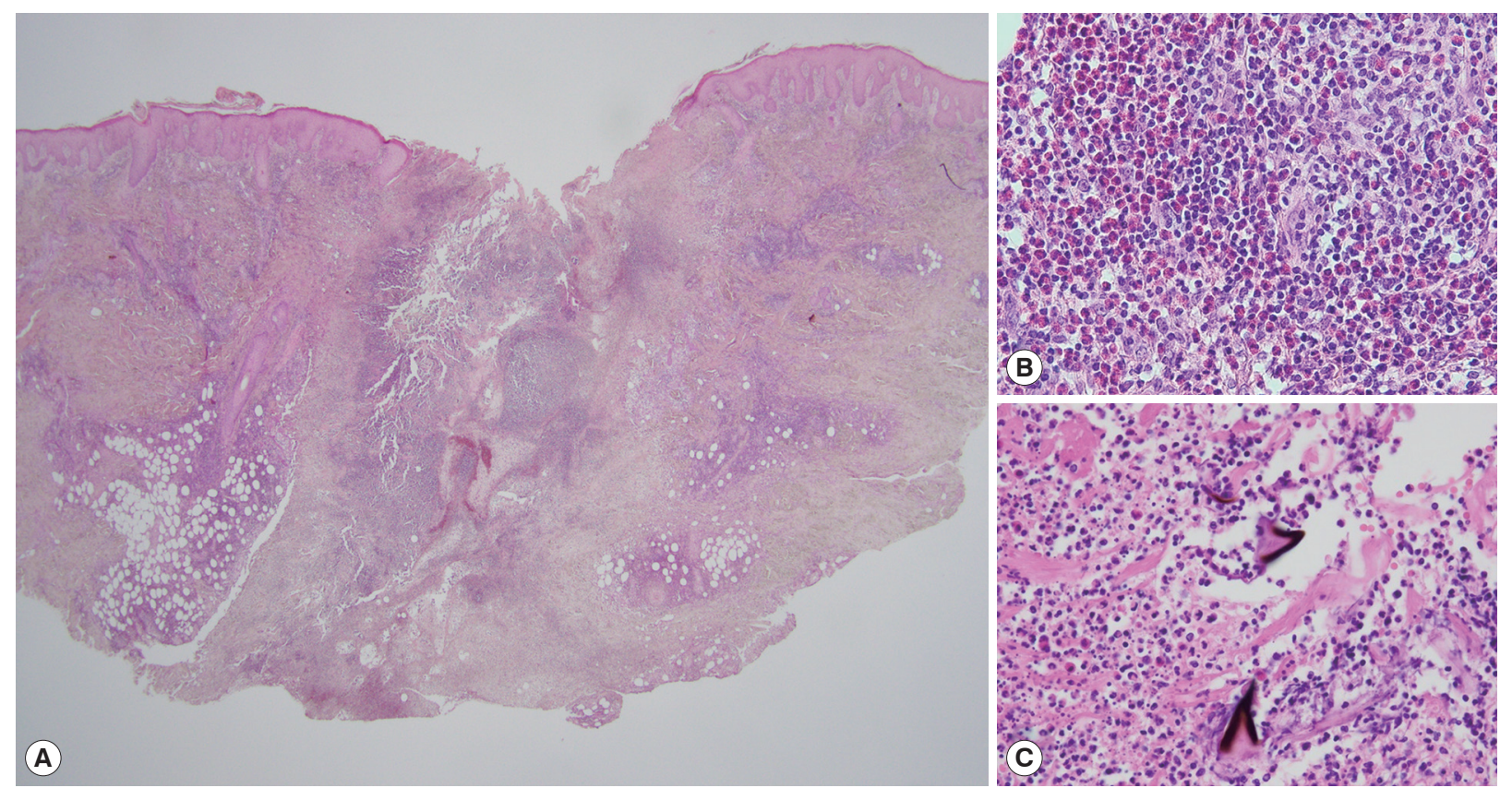

Fig. 2. (A) Skin biopsy from the nodule on the buttock showed ulceration, central fibrinoid necrosis and diffuse cellular infiltration in the dermis $(H \& E, \times 1.25)$. (B) A high power view revealed the infiltration of inflammatory cells that consisted of lymphocytes, eosinophils and neutrophils $(H \& E, \times 400)$. (C) Skin biopsy from upper thigh specimen, several brownish angular fragments were identified, which were thought to be remnants of larvae (H\&E, $\times 400)$. 


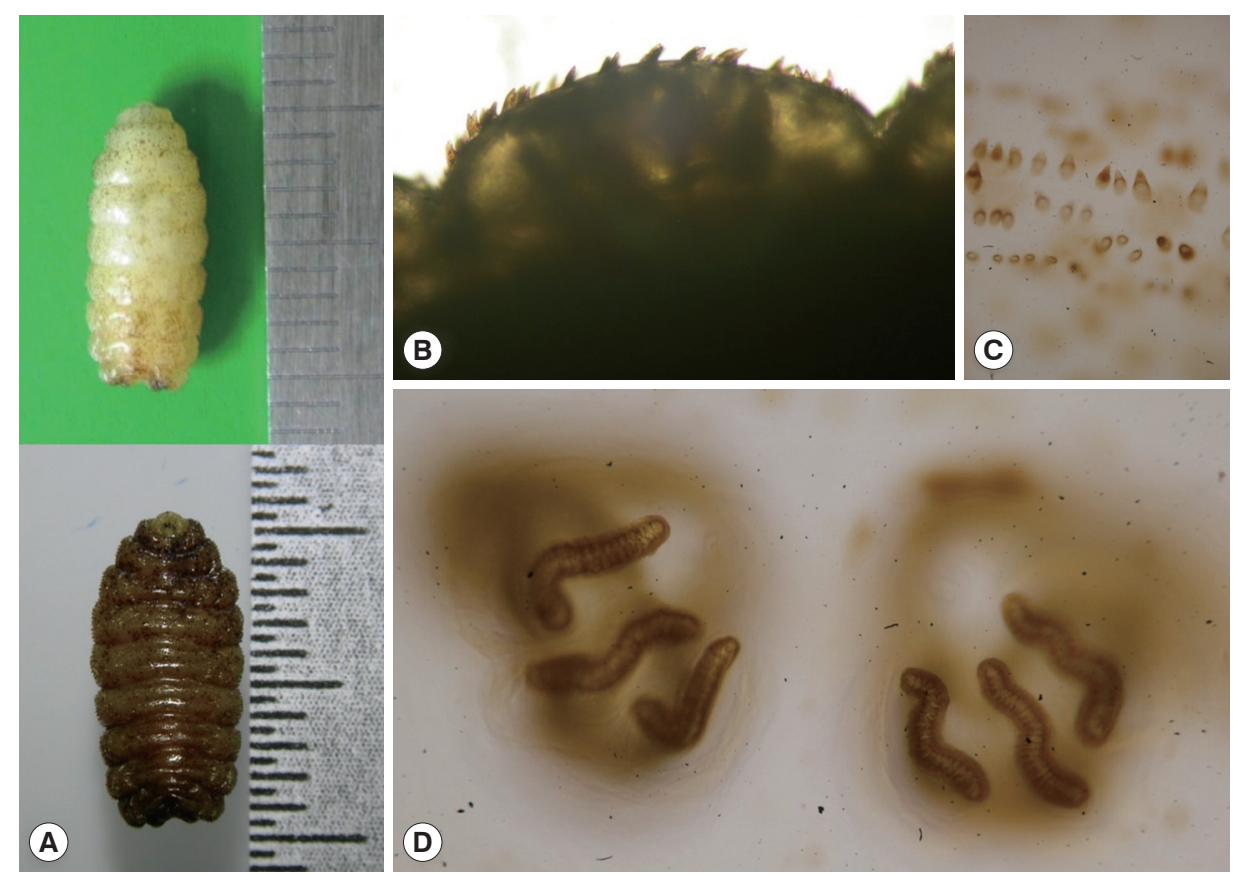

Fig. 3. (A) Two white and dark-brown colored barrel-shaped larvae were about $10.5 \mathrm{~mm}$ in length, and $4.5 \mathrm{~mm}$ in width. (B) Their body was almost completely covered by conic spines with a brown apex, pointing towards the posterior end. (C) Detail of cuticle spines. (D) Two copper-colored posterior spiracles, each bearing 3 sinuous spiracular slits which lack a distinct chitinous rim.

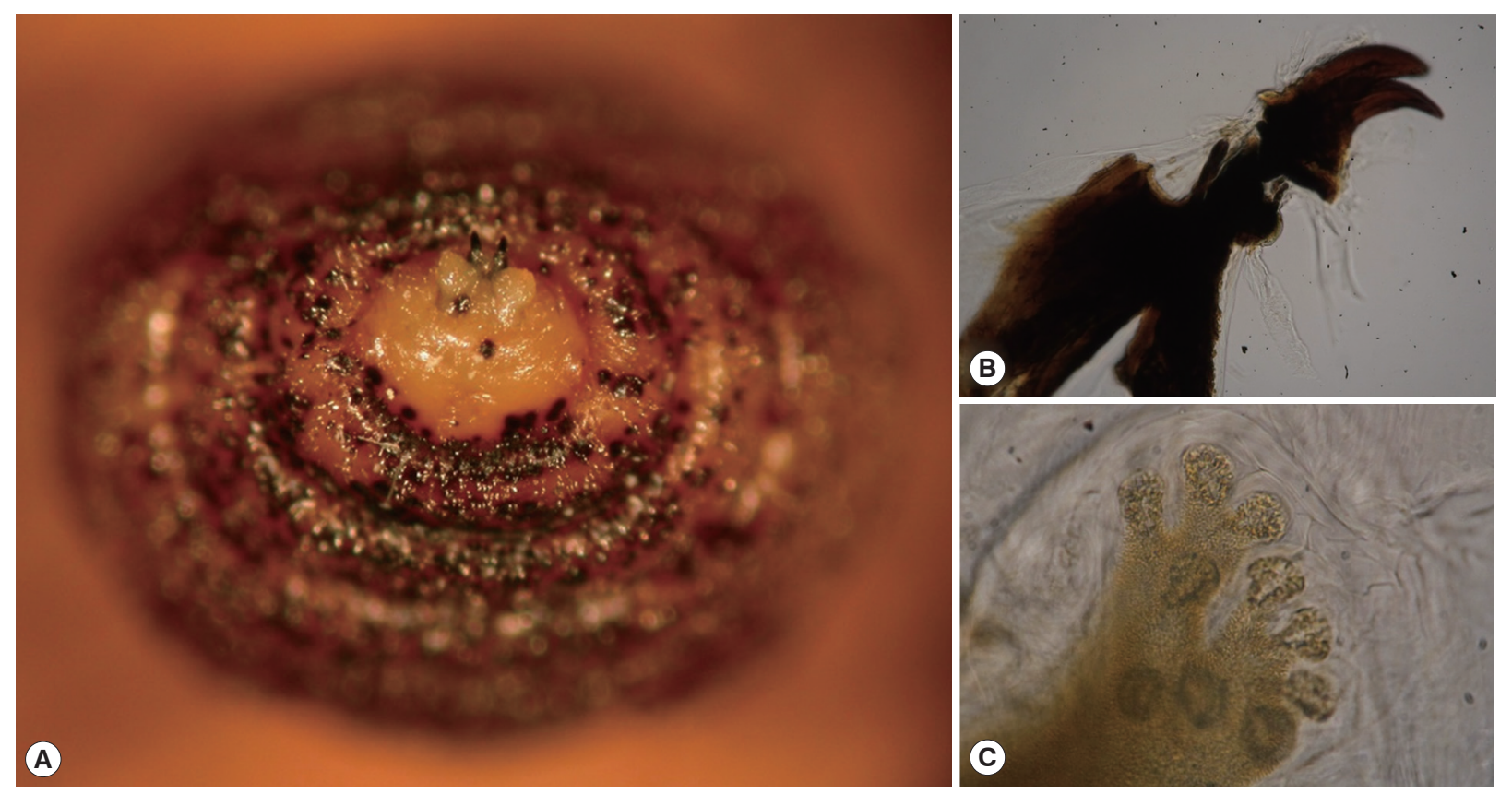

Fig. 4. (A) Anterior end of larva. (B) Paired mouth hooks (toothed, spade-like, oral hooklets) protruded ventrally from anterior end. (C) Anterior spiracles of larva.

central fibrinoid necrosis and diffuse cellular infiltration of lymphocytes, eosinophils and neutrophils in deep dermis (Fig. 2A, B). The upper thigh specimen showed gangrenous necrosis and cellular infiltration extending to subcutis and several deep brownish angular fragments were observed in dermis, which were thought to be remnants of larvae (Fig. 2C). Two barrel- 
shaped larvae were detected from the each lesion. They were white and dark-brown colored, $10.5 \mathrm{~mm}$ long and $4.5 \mathrm{~mm}$ wide (Fig. 3A).

The larvae were preserved in a solution of $10 \% \mathrm{KOH}, 89 \%$ ethanol, 95\% ethanol, and 100\% ethanol sequentially. The morphology of their body was almost completely covered by conic spines with a brown apex, pointing towards the posterior end (Fig. 3B, C). Two copper-colored posterior spiracles, each bearing 3 sinuous spiracular slits which lack a distinct chitinous rim (Fig. 3D). In the anterior end of larva, the mouth with a pair of spade-like stout hooks and anterior spiracles were characteristically observed (Fig. 4). Skin lesions were markedly improved after the remove of larvae and 2-week antibiotic treatment, and there was no recurrence.

\section{DISCUSSION}

C. anthropophaga is known as the skin maggot fly, the mango fly, the putzi (or putsi) fly, by the French name ver du Cayer ("worm of Cayer", an area in present-day Senegal) or, most commonly the tumbu fly [1]. The adult fly is yellow brown, has brown-black spots on the abdomen, 2 black longitudinal bands on the thorax, and measure 6 to $12 \mathrm{~mm}$ in length [7].

The larvae can penetrate the unbroken skin of the host, who is usually lying on the ground or by the contaminated clothes. Interestingly, the host usually feels no symptoms at the time of skin penetration by larvae. Therefore, most patients do not think maggots as a cause of their skin problems. Within 1 to 2 weeks, the larvae develop into the second and third instars, and the 13- to 15-mm sized mature larvae that can emerge from the central pore of the skin lesions [3]. In this report, morphological characteristics of larvae of $C$. anthropophaga (ex, a pair of spade-like hooks, anterior spiracles, and posterior spiracles) are well observed in Figs. 3 and 4.

Early lesions may resemble other reactions due to insect bite, but furuncular lesions with an intense inflammatory reaction in the surrounding tissue rapidly develop $[3,8]$. The goal of treatment is removal of the larva and prevention of the secondary infection. Occlusion, larvicides such as ivermectin, or manual squeezing can be used to remove the larva. Occlusion deprives the larva of oxygen and either kills the larva or induces it to move upward in search of air [1]. Manually squeezing out the larva is therapeutic option in all forms of furuncular myiasis. Sometimes, surgical removal is needed for removing the larvae or their fragments [9]. Indeed, our case showed sev- eral fragments of larvae and surrounding necrosis and granuloma formation. For our patient, we believe that removing the ulcer, probably opening pore, through biopsy procedure helped the patient's recovery.

Furuncular myiasis is common in tropical and subtropical areas, including central and South America, tropical Africa, however, there are few reported cases of furuncular or wound myiasis in Korea. Three patients were Korean [4-6] and the other 2 were foreigners who lived in Korea [10,11]. Three patients were furuncular myiasis caused by $C$. anthropophaga from Cameroon and Uganda $[4,6]$ and D. hominis from Cost Rica [5]. Two foreigners had C. anthropophaga from Benin [10] and D. hominis from South America [11]. These traveling history are consistent with endemic geographic location of $C$. anthropophaga and D. hominis. Actually, C. anthropophaga is most commonly found in tropical African and D. hominis is most commonly found in Central and South America. Our cases also have traveling history to Equatorial Guinea, Central Africa. It has been reported in other northeast Asia countries, that is, China and Japan [12-14]. Therefore, although northeast Asia is not common location of furuncular myiasis, with increasing international travels and works, myiasis may be encountered more frequently.

In conclusion, we report a case of furuncular cutaneous myiasis on the left side of the buttock and upper thigh by $C$. anthropophaga, which has been rarely described in Korea. Considering the increasing international travel and exchange workers with foreign countries, physicians should be more concerned about clinical manifestations of cutaneous myiasis and morphologic characteristics of diphterous larvae.

\section{CONFLICT OF INTEREST}

We have no conflict of interest related to this study.

\section{REFERENCES}

1. McGraw TA, Turiansky GW. Cutaneous myiasis. J Am Acad Dermatol 2008; 58: 907-926.

2. Robbins K, Khachemoune A. Cutaneous myiasis; a review of the common types of myiasis. In J Dermatol 2010; 49: 1092-1098.

3. Ockenhouse CF, Samlaska CP, Benson PM, Roberts LW, Eliasson A, Malane S, Menich MD. Cutaneous myiasis caused by the African tumbu fly (Cordylobia anthropophaga). Arch Dermatol 1990; 126: 199-202.

4. Park JM, Kim HJ, Choi YJ, Yong TS, Ree HI, Lee MG. A case of 
furuncular cutaneous myiasis after traveling to Cameroon. Korean J Dermatol 2009; 47: 600-603 (in Korean).

5. Youn YH, Kim MR, Oh ST, Cho BK, Lee IY, Park HJ. A case of furuncular cutaneous myiasis by Dermatobia hominis. Korean J Dermatol 2015; 53: 570-571 (in Korean).

6. Song SM, Kim SW, Goo YK, Hong Y, Ock MS, Cha HJ, Chung DI. A case of furuncular myiasis due to Cordylobia anthropophaga in a Korean traveler returning from Uganda. Korean J Parasitol 2017; 55; 327-331.

7. Veraldi S, Brusasco A, Süss L. Cutaneous myiasis case by larvae of Cordylobia anthropophaga (Blanchard). Int J Dermatol 1993; 32: 184-187.

8. Chopra A, Probert AJ, Beer WE. Myiasis due to tumbu fly. Lancet 1985; 1: 1165.

9. Lane RP, Lowell CR, Griffiths WA, Sonnex TS. Human cutaneous myiasis--a review and report of three cases due to Dermatobia hominis. Clin Exp Dermatol 1987; 12: 40-45.
10. Ko BJ, Cho HK, Lee IY, Yong TS, Whang KU. A case of furuncular cutaneous myiasis in a German patient who has traveled to Benin. Korean J Dermatol 2013; 51: 348-352 (in Korean).

11. Shin JY, Kim JH, Kim YC. Furuncular myiasis in a traveler returning from South America. Korean J Dermatol 2012; 50: 662-663 (in Korean).

12. Deng Y, Liu F, Chen X, Lu S. The first imported cutaneous myiasis due to Cordylobia anthropophaga in China. Int J Dermatol 2013; 52: 120-122.

13. Fujisaki R, Makimura K, Hayashi T, Yamamura M, Yamaoka T, Shiraishi K, Ishibashi S, Kawakami S, Kurihara T, Nishiya H. Exotic myiasis caused by 19 larvae of Cordylobia anthropophaga in Namibia and identified using molecular methods in Japan. Trans R Soc Trop Med Hyg 2008; 102: 599-601.

14. Nagamori K, Katayama T, Kumagai M. A case of cutaneous myiasis due to Dermatobia hominis in Japan. J Infect Chemother 2007; 13: 255-257. 
